\title{
THE BEHAVIOR OF THE ORBITS OF POWER BOUNDED OPERATORS
}

\author{
H. S. MustafayeV
}

Abstract. Let $T$ be a power bounded operator on a Banach space $X$ and let $\sigma_{T}(x)$ be the local spectrum of $T$ at $x \in X$. In this paper, we study the asymptotic behavior of the orbits $\left\{T^{n} x: n \geqslant 0\right\}$ in terms of the local spectrum of $T$ at $x$. Mathematics subject classification (2010): 47A11, 47A35, 43A46.

Keywords and phrases: Power bounded operator, local spectrum, Helson set, Sidon set, stability.

\section{REFERENCES}

[1] G. R. Allan And T. J. Ransford, Power-dominated elements in a Banach algebra, Studia Math., 94 (1989), 63-79.

[2] C. J. K. BATTY, J. VAN NEERVEN AND F. RÄBIGER, Local spectra and individual stability of uniformly bounded $C_{0}$-semigroups, Trans. Amer. Math. Soc., 350 (1998), 2071-2085.

[3] B. BeauZamy, Introduction to Operator Theory and Invariant Subspaces, North-Holland, Amsterdam, 1988.

[4] J. Benedetto, Harmonic Analysis on Totally Disconnected Sets, Lecture Notes in Math., 202, Springer-Verlag, 1971.

[5] R. P. BoAs, Entire Functions, Academic Press, New York, 1954.

[6] I. M. GELFAND, Zur theorie der charactere der abelschen topologischen gruppen, Rec. Math. N. S. (Mat. Sb), 51 (1941), 49-50.

[7] E. A. GoRIn, Bernstein's inequality from the point of view of operator theory, Selecta Math. Soviet, 7 (1988), 191-209 (transl. from Vestnik Kharkov Univ. 45 (1980), 77-105).

[8] Y. KATZNELSON AND L. TZAFRIRI, On power bounded operators, J. Funct. Anal., 68 (1986), 313 328.

[9] L. Kérchy And J. VAn NeErven, Polynomially bounded operators whose spectrum on the unit circle has measure zero, Acta Sci. Math. (Szeged), 63 (1997), 551-562.

[10] R. LARSEN, Banach Algebras, Marcel-Dekker Inc., New York, 1973.

[11] Z. LeKA, A Katznelson-Tzafriri type theorem in Hilbert spaces, Proc. Amer. Math. Soc., 137 (2009), $3763-3768$.

[12] B. YA. Levin, Distributions of Zeros of Entire Functions, Amer. Math. Soc. Providence, 1964.

[13] L. H. Loomis, The spectral characterization of a class of almost periodic functions, Ann. Math., 72 (1960), 362-368.

[14] H. S. Mustafayev, The Banach algebra generated by a contraction, Proc. Amer. Math. Soc., 134 (2006), 2677-2683.

[15] H. S. Mustafayev, Asymptotic behavior of polynomially bounded operators, C. R. Acad. Sci. Paris, Ser. I, 348 (2010), 517-520.

[16] B. Sz.-Nagy and C. Foias, Harmonic Analysis of Operators on Hilbert Space, (Russian), Mir, Moscow, 1970.

[17] J. VAn NeERven, The Asymptotic Behavior of Semigroups of Linear Operators, Oper. Theory Adv. Appl., 88, Birkhäuser Verlag, Basel, 1996.

[18] B. Nyman, On the one-dimensional translation group and semi-group in certain function spaces, Inaugural Dissertation, Uppsala, 1950.

[19] W. Rudin, Fourier Analysis on Groups, Wiley-Interscience Publication, New-York, 1962.

[20] W. Rudin, Trigonometric series with gaps, J. Math. Mech., 9 (1960), 203-228. 